\title{
Demographic, clinical, lifestyle-related, and social-cognitive correlates of physical activity in head and neck cancer survivors
}

\author{
Laurien M. Buffart ${ }^{1,2,3} \cdot$ Remco de Bree $^{4,5} \cdot$ Martine Altena $^{6} \cdot$ Sophie van der Werff ${ }^{7}$. \\ Constance H. C. Drossaert ${ }^{6}$. Caroline M. Speksnijder ${ }^{8,9,10}$ • Michiel W. van \\ den Brekel ${ }^{11}$ - Harriët Jager-Wittenaar ${ }^{12,13}$ • Neil K. Aaronson ${ }^{14}$. \\ Martijn M. Stuiver ${ }^{7,11,15}$
}

Received: 23 December 2016/Accepted: 9 November 2017 /Published online: 18 November 2017

(C) The Author(s) 2017. This article is an open access publication

\begin{abstract}
Purpose The purpose of the study is to identify demographic, clinical, lifestyle-related, and social-cognitive correlates of physical activity (PA) intention and behavior in head and neck cancer (HNC) survivors using the theory of planned behavior (TPB).

Methods Data from two cross-sectional studies on correlates of PA in HNC survivors were pooled. Both studies used selfreports to assess PA and social-cognitive correlates. Potential correlates were collected via self-report or medical records. Univariable and multivariable multilevel linear mixed-effects models were built to identify correlates of PA intention and PA behavior ( $Z$ scores). Structural equation model analyses were
\end{abstract}

Laurien M. Buffart

1.buffart@vumc.nl

1 Department of Epidemiology and Biostatistics, Amsterdam Public Health Research Institute, VU University Medical Center, De Boelelaan 1089a, 1081 HV Amsterdam, The Netherlands

2 Department of Medical Oncology, Cancer Center Amsterdam, VU University Medical Center, Amsterdam, The Netherlands

3 Exercise Medicine Research Institute, Edith Cowan University, Joondalup, Australia

4 UMC Utrecht Cancer Center, Department of Head and Neck Surgical Oncology, University Medical Center Utrecht,

Utrecht, The Netherlands

5 Department of Otolaryngology-Head and Neck Surgery, VU University Medical Center, Amsterdam, The Netherlands

6 Center of eHealth and Wellbeing Research, University of Twente, Enschede, The Netherlands

7 Department of Physical Therapy, Netherlands Cancer Institute, Amsterdam, The Netherlands conducted to study the full TPB model in one analysis, taking into account relevant covariates.

Results In total, $416 \mathrm{HNC}$ survivors were surveyed. Their mean (SD) age was 66.6 (9.4) years; 64\% were men, and $78 \%$ were diagnosed with laryngeal cancer. The structural equation model showed that PA intention was significantly higher in HNC survivors with a history of exercising, who had a more positive attitude, subjective norm, and perceived behavioral control. Patients with higher PA intention, higher $\mathrm{PBC}$, a lower age, and without unintentional weight loss or comorbidities had higher PA behavior. The model explained $22.9 \%$ of the variance in PA intention and $16.1 \%$ of the variance in PA behavior.
8 Physical Therapy Science, Program in Clinical Health Sciences, University Medical Center Utrecht, Utrecht, The Netherlands

9 Department of Oral-Maxillofacial Surgery, Prosthodontics and Special Dental Care, University Medical Center Utrecht, Utrecht, The Netherlands

10 Julius Center Sciences, University Medical Center Utrecht, Utrecht, The Netherlands

11 Department of Head and Neck Oncology and Surgery, Netherlands Cancer Institute, Amsterdam, The Netherlands

12 Research Group Healthy Ageing, Allied Health Care and Nursing, Hanze University of Applied Sciences, Groningen, The Netherlands

13 Department of Maxillofacial Surgery, University of Groningen, University Medical Center Groningen, Groningen, The Netherlands

14 Division of Psychosocial Research \& Epidemiology, Netherlands Cancer Institute, Amsterdam, The Netherlands

15 ACHIEVE Centre of Applied Research, Faculty of Health, Amsterdam University of Applied Sciences, Amsterdam, The Netherlands 
Conclusions Despite significant pathways of the TPB model, the large proportion variance in PA intention and behavior remaining unexplained suggests the need for better PA behavior (change) models to guide the development of PA promotion programs, particularly for the elderly. Such programs should be tailored to comorbidities and nutritional status.

Keywords Exercise $\cdot$ Social-cognitive models $\cdot$ Head and neck neoplasm

\section{Introduction}

There is increasing evidence from randomized controlled trials that regular physical activity (PA) has beneficial effects on health and health-related quality of life (HRQoL) in cancer survivors [31, 32, 42]. PA levels of cancer survivors tend to decrease during cancer treatment. Although they increase during the post-treatment period, they typically do not return to pre-treatment levels [12, 21].

Little is known about the PA behavior of survivors of head and neck cancer (HNC). During treatment, HNC survivors often face severe treatment-related toxicities that differ from survivors of other types of cancer, and they may be at high risk of malnutrition [20]. In addition, a substantial proportion of HNC survivors have suboptimal health literacy [27]. This may impact short-term and long-term PA behavior. Results from a recent survey among $172 \mathrm{HNC}$ survivors showed a decrease in PA from pre-treatment to post-treatment [39]. Patients with higher levels of PA post-treatment had higher HRQoL [39]. A previous cross-sectional study among $59 \mathrm{HNC}$ survivors who were on average 18 months after diagnosis showed that only a small proportion of HNC survivors participated in moderate to vigorous PA, and those who had higher levels of PA were less fatigued and had a higher HRQoL [36]. HNC survivors have reported various barriers to becoming physically active, including $\mathrm{HNC}$-specific symptoms such as dry mouth, difficulty with eating, shortness of breath, and muscle weakness [35]. In addition to treatment-related symptoms, social-cognitive factors, such as enjoying being physically active, were most strongly correlated with PA [35].

Understanding correlates of PA behavior may aid the development of interventions promoting PA behavior for $\mathrm{HNC}$ survivors. Interventions based on behavior change theories have been shown to be more effective in improving behavior than those not based on theory [19], and interventions based on a social-cognitive model have shown to be promising to improve PA behavior in cancer survivors [44].

In survivors of other types of cancer, including breast, colorectal, prostate, bladder, gynecological, and kidney cancer $[7,13,24,25,43,45]$, the theory of planned behavior (TPB) has been used to identify correlates of PA behavior. The TPB postulates that intention is the immediate determinant of behavior because it reflects a conscious decision to perform or not perform the behavior [5]. Intention, in turn, is determined by three conceptually distinct constructs: attitude, subjective norm, and perceived behavioral control (PBC). An attitude is a person's state of mind regarding certain objects and behaviors, in this case PA. Attitudes are primarily shaped by personal experiences. Subjective norm represents the perceived social pressure that individuals may feel to perform or not perform the behavior. PBC refers to the belief that one is capable of executing a certain course of action, and it may directly predict behavior if it is an accurate reflection of actual control, also known as self-efficacy [5]. In previous studies in cancer survivors, intention and $\mathrm{PBC}$ have explained $14-42 \%$ of the variance in PA, and attitude, subjective norm and PBC 23-69\% of the variance in intention, with variations across cancer types [7, 13, 24, 25, 43, 45].

Except for a few pilot studies [30,53], PA interventions in $\mathrm{HNC}$ survivors have primarily focused on functional training to prevent speech, swallowing, and shoulder problems [1, 10, 11], rather than on improving PA to promote physical fitness and health [20]. Because of the scarcity of information on PA and its social-cognitive correlates in HNC survivors, and to aid in the development of future theory-based interventions to promote PA in this population, we aimed to identify socialcognitive correlates of PA using the TPB model in addition to demographic, clinical, and lifestyle-related correlates in a large group of HNC survivors.

\section{Methods}

To increase sample size for the current analysis, we pooled data from two cross-sectional studies that used similar questions to assess social-cognitive variables. In the first study (further referred to as the Laryngectomy study), all members from the Dutch Association for Laryngectomized Patients living in the Netherlands were invited to complete a survey in May 2014, either online or via the regular mail. The study was approved by the Medical Ethics Committee of the VU University Medical Center.

In the second study (further referred to as $\mathrm{HNC}_{\text {mixed }}$ study), a mail survey was sent to adult survivors of a primary head and neck squamous cell carcinoma living in the Netherlands, who were treated with curative intent within the past 5 years. Eligible patients for this study were identified via the tumor registry of the Netherlands Cancer Institute. This study was approved by the Medical Ethics Committee of the Netherlands Cancer Institute. In both studies, a single reminder was sent to initial nonresponders after 2 or 3 weeks. All participants signed an informed consent statement prior to participation. 


\section{Assessment of physical activity}

Both studies measured PA using self-report. The Laryngectomy study used the 13-item Physical Activity Scale for the Elderly (PASE) questionnaire [50, 51]. Participants were asked to report the frequency and duration of leisure time, household, and work-related physical activities in the past 7 days. The frequency of activities was recorded as never, seldom ( 1 to 2 days/week), sometimes (3 to 4 days/week), or often (5 to 7 days/week). Duration of activities, except work, was categorized as less than $1 \mathrm{~h}$, between 1 and $2 \mathrm{~h}$, between 2 and $4 \mathrm{~h}$, or more than $4 \mathrm{~h}$. Work was categorized as less than $1 \mathrm{~h}$, between 1 and $4 \mathrm{~h}$, between 5

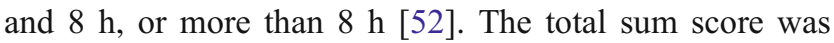
computed by multiplying the amount of time spent on each activity in (hours/week) by the published empirically derived item weights and summing over all the activities [50]. The PASE has good content validity and good to excellent testretest reliability in patients with cancer [29].

The $\mathrm{HNC}_{\text {mixed }}$ study used the long version of the Dutch International Physical Activity Questionnaire (IPAQ) [14], which assesses leisure time, household, transportation, and work-related physical activities over the past week. The IPAQ has good test-retest reliability, and evidence supports its construct validity in the general population of multiple countries [14]. The IPAQ contains four PA domains: (1) work; (2) transportation; (3) house work, house maintenance, and caring for family; and (4) recreation, sport, and leisure time. In addition, it measures the amount of time spent sitting. Time spent in each of the domains was multiplied by corresponding metabolic equivalent of task (MET) values (representing the factor by which resting metabolism increases due to the activity) [2-4], resulting in sum scores for total PA in MET minutes per week.

To pool the data from the two questionnaires, we calculated $Z$ scores for each participant by subtracting the sample means and dividing by the standard deviation of the respective scores of each questionnaire. Because the distributions of the data from both questionnaires were skewed to the right, we logtransformed the data before calculating the $Z$ scores.

\section{Demographic, clinical, and lifestyle-related variables}

Demographic characteristics were obtained by self-report and included age, sex, education (higher vocational education or university versus lower), and having a partner.

Clinical data were collected from medical records ( $\mathrm{HNC}_{\text {mixed }}$ study) or by self-report (Laryngectomy study) and included diagnosis, time since treatment, type of treatments, and comorbidity. The number of different treatment types was dichotomized into $<2$ versus $\geq 2$. Comorbidity was dichotomized into none versus one or more of the following not further specified comorbidities: pulmonary diseases, diabetes, cardiovascular disease, kidney diseases, neurological diseases, thyroid disease, rheumatic disorders, or musculoskeletal problems. As an indicator of malnutrition risk, participants filled out a single-item question reporting whether or not they recently lost weight unintentionally.

Current alcohol consumption was assessed by self-report and dichotomized into any or none. Body mass index (BMI) was calculated from self-reported height and weight. Exercise history was assessed by self-report and categorized as yes, if patients had exercised prior to diagnosis, and otherwise as no.

\section{Constructs of the theory of planned behavior}

Intention was assessed by a single item "I intend to exercise regularly over the next month," rated on a seven-point Likert scale (strongly disagree to strongly agree). The score was linearly transformed to $0-100$, with a higher score representing a more positive intention towards PA.

Attitude was assessed by seven bipolar adjective scales covering affective (enjoyable-unenjoyable, interesting-boring, pleasant-unpleasant) and instrumental (useful-useless, beneficial-harmful, wise-foolish, good-bad) aspects of attitude. The statements were preceded by "physical activity is...." The Cronbach's alphas for the affective and instrumental attitude scales were 0.93 and 0.87 , respectively, and the correlation $\left(r_{p}\right)$ between the two scales was 0.75 . We combined the two scales into an overall attitude scale $(\alpha=0.94)$, and the mean score of the seven items was linearly transformed to 0-100 and used for further analysis. A higher score represents a more positive attitude towards PA.

Subjective norm was assessed by a single item: "Most people who are important to me think I should exercise regularly" rated on a five or seven-point Likert scale (strongly disagree to strongly agree). Scores were linearly transformed to 0-100, with a higher score representing a more positive subjective norm regarding $\mathrm{PA}$.

Perceived behavioral control was assessed by rating the perceived confidence in being able to exercise regularly in four different situations, including bad weather, having no interest, having physical complaints, and being under personal stress. Items were scored on a five or seven-point Likert scale (strongly disagree to strongly agree), and scores were linearly transformed to $0-100$. Crohnbach's alpha for the scale was 0.81 , and we used the mean score for further analysis. Higher scores represent a higher PBC.

\section{Statistical analysis}

Descriptive information of normally distributed variables is presented as mean and standard deviation (SD), and we used median and interquartile range (IQR) otherwise.

Univariable and multivariable multilevel linear mixedeffect models were built to identify correlates of PA intention and PA behavior ( $Z$ scores), in which the clustering of patients 
within studies was taken into account by using a random intercept on study level. Multivariable models were built in two steps. First, we selected the demographic, clinical, and lifestyle-related correlates using a backward selection procedure, in which variables with $p>0.10$ were removed from the model one by one. In the second step, we entered the socialcognitive variables into the regression models obtained in step 1. The models' regression coefficients and 95\% confidence intervals (CI) are presented. Marginal explained variances of the models were calculated $[22,33]$. These analyses were conducted in IBM SPSS Statistics 22 and R 3.3.

Next, we used a structural equation model (SEM) to examine the full TPB model in one analysis, including relevant demographic, clinical, and lifestyle-related correlates selected from the linear mixed-effect models using the piecewise SEM package in R [28]. Model fit was evaluated using Shipley's test of directed separation [40], which uses Fisher's $C$ statistic [41]. A significant Shipley's test indicates that there are one or more relationships between the variables in the model that are not yet included in the model.

\section{Results}

In total, 284 (response rate 33\%) HNC survivors participated in the Laryngectomy study, of whom 142 completed the survey online and 142 via paper and pencil, and 132 (response rate $52 \%$ ) $\mathrm{HNC}$ survivors participated in the $\mathrm{HNC}_{\text {mixed }}$ study. Consequently, survey data from $416 \mathrm{HNC}$ survivors were available for the current analyses.

Participants were on average 66.6 (SD 9.4) years old; 64\% were men, and $78 \%$ were diagnosed with cancer of the larynx (Table 1). Median time since treatment was 54 months, and $70 \%$ were treated with multiple treatment modalities. Unintentional weight loss was present in $11 \%$ of participants, and comorbidities were present in $37 \%$, with cardiovascular problems $(20 \%)$, musculoskeletal problems (11\%), and thyroid disease $(9 \%)$ rated as most common problems.

Mean scores on TPB variables ranged from 51.7 for PBC to 80.0 for attitude. Median PASE score of participants from the Laryngectomy study was 106.7 , and median IPAQ score of participants from the $\mathrm{HNC}_{\text {mixed }}$ study was 3510 MET minutes/week (Table 1).

\section{Correlates of physical activity intention and behavior}

Univariable and multivariable associations with PA intention and PA behavior are presented in Tables 2 and 3, respectively. PA intention was significantly higher in HNC survivors who had a history of exercising (Table 3 ). No significant associations were found for demographic and clinical characteristics. HNC survivors with more positive attitudes, subjective norms, and $\mathrm{PBC}$ had higher PA intention.
PA behavior was significantly higher in HNC survivors who were younger, had not lost weight unintentionally, and had no comorbidities (Table 3). Additionally, PA intention and $\mathrm{PBC}$ were significantly associated with PA behavior.

Also, the path analysis showed that a more positive attitude, subjective norm, and PBC and a history of exercising were associated significantly with a higher PA intention and that a higher PA intention, PBC, a younger age, and the absence of unintentional weight loss and comorbidities were associated significantly with a higher PA behavior (Table 4, Fig. 1). The model explained $22.9 \%$ of PA intention and $16.1 \%$ of PA behavior. Fisher's $C$ of the SEM model was $27.48(\mathrm{df}=14, p=0.017)$, suggesting that one or more relationships between the variables were not included in the model. The missing path analysis indicated a direct path from attitude to PA behavior. Adding this association to the SEM model increased the explained variance for PA behavior to $19.1 \%$ and improved the model fit $(C=14.4, \mathrm{df}=12, p=$ $0.276)$.

\section{Discussion}

This study evaluated the TPB model in a relatively large group of HNC survivors and showed that attitude, subjective norm, and $\mathrm{PBC}$ were significantly associated with PA intention and that $\mathrm{PA}$ intention and $\mathrm{PBC}$ were significantly associated with PA behavior. Additionally, we found higher PA intention in HNC survivors who had a history of exercising and higher PA behavior in survivors who were younger, and without unintentional weight loss and comorbidities. However, the model explained only a small proportion of the variance in PA intention and PA behavior.

Overall, the TPB model explained $22.9 \%$ of the variance in $\mathrm{PA}$ intention and $16.1 \%$ of the variance in PA behavior. Although, this is comparable to the 23 and $14 \%$, respectively, reported in a study of women during treatment for breast cancer [13], it is generally low compared to findings in studies that applied the TPB model in other types of cancer [7, 24, 25, $43,45]$. The current study confirms the relevance of socialcognitive constructs in explaining PA behavior in HNC survivors observed in previous research [35, 37]. The low amount of variance in PA intention and behavior explained and the poor model fit indicate the need for better suitable or additional behavior theories to explain behavior in $\mathrm{HNC}$ survivors that can assist in developing interventions to promote PA behavior. In fact, a better model fit was found when attitude was directly associated with PA behavior, indicating that the behavior is not fully intentional. This intention-behavior gap has previously been acknowledged [34], also in survivors of cancer types other than HNC [46]. Coping and planning, i.e., the anticipation of PA barriers and the design of alternative actions, as well as coping and maintenance self-efficacy, are 
Table 1 Descriptive values of demographic, clinical, and lifestyle-related characteristics, social cognitive variables, and physical activity of $\mathrm{HNC}$ survivors $(n=416)$

\begin{tabular}{|c|c|c|c|}
\hline & Laryngectomy & $\mathrm{HNC}_{\text {Mixed }}$ & Total \\
\hline \multicolumn{4}{|l|}{ Demographic variables } \\
\hline$N$ & 284 & 132 & 416 \\
\hline Age, mean (SD) (years) & $67.9(8.8)$ & $63.6(10.1)$ & $66.6(9.4)$ \\
\hline Gender, $n(\%)$ male & $237(84)$ & $102(77)$ & $339(82)$ \\
\hline Partner, $n(\%)$ yes & $202(71)$ & $103(78)$ & $305(73)$ \\
\hline Education, $n(\%)$ high & $56(20)$ & $42(32)$ & $98(24)$ \\
\hline \multicolumn{4}{|l|}{ Clinical variables } \\
\hline \multicolumn{4}{|l|}{ Diagnosis, $n(\%)$} \\
\hline Larynx & $284(100)$ & $40(30)$ & $324(78)$ \\
\hline Other & $0(0)$ & $92(70)$ & $92(22)$ \\
\hline \multicolumn{4}{|l|}{ Treatment, $n(\%)$} \\
\hline Laryngectomy & $284(100)$ & $2(2)$ & $286(69)$ \\
\hline Surgery other & $0(0)$ & $40(30)$ & $40(10)$ \\
\hline Radiotherapy & $250(89)$ & $62(50)$ & $312(76)$ \\
\hline Chemotherapy & $27(10)$ & $11(8)$ & $38(9)$ \\
\hline Chemoradiation & NA & $35(27)$ & $35(8)$ \\
\hline PDT & $0(0)$ & $6(5)$ & $6(1)$ \\
\hline Brachytherapy & $0(0)$ & $5(4)$ & $5(1)$ \\
\hline $\mathrm{CO}_{2}$ laser & $0(0)$ & $13(10)$ & $13(3)$ \\
\hline Multiple treatment modalities & $250(88)$ & $39(30)$ & $289(70)$ \\
\hline Time since treatment, median (IQR) (months) & $78(36 ; 168)$ & $44(32 ; 53)$ & $54(33 ; 120)$ \\
\hline Comorbidity $^{\mathrm{a}}, n(\%)$ & $113(40)$ & $41(31)$ & $154(37)$ \\
\hline Lung disease & $26(9)$ & $5(4)$ & $31(12)$ \\
\hline Cardiovascular disease & $16(6)$ & $5(4)$ & $21(8)$ \\
\hline Diabetes & $59(21)$ & $20(15)$ & $79(19)$ \\
\hline Kidney disease & $5(2)$ & $1(1)$ & $6(1)$ \\
\hline Neurological disease & $4(1)$ & $4(3)$ & $8(2)$ \\
\hline Rheumatic disease & $27(10)$ & $0(0)$ & $27(6)$ \\
\hline Musculoskeletal problems & $29(10)$ & $15(11)$ & $44(11)$ \\
\hline Thyroid disease & $35(12)$ & $4(3)$ & $39(9)$ \\
\hline Unintentional weight loss, $n(\%)$ & $27(10)$ & $18(14)$ & $45(11)$ \\
\hline BMI, mean (SD) $\left(\mathrm{kg} / \mathrm{m}^{2}\right)$ & $26.1(4.8)$ & $24.6(3.6)$ & $25.6(4.5)$ \\
\hline Underweight $(\mathrm{BMI}<18.5), n(\%)$ & $3(1)$ & $3(2)$ & $6(1)$ \\
\hline Normal weight (BMI 18.5-25), $n(\%)$ & $122(43)$ & $74(56)$ & $196(47)$ \\
\hline Overweight (BMI 25-30), $n(\%)$ & $113(40)$ & $48(36)$ & $161(39)$ \\
\hline Obese $(\mathrm{BMI} \geq 30), n(\%)$ & $44(16)$ & $7(5)$ & $51(12)$ \\
\hline \multicolumn{4}{|l|}{ Lifestyle-related variables } \\
\hline Current alcohol consumption, $n(\%)$ yes & $199(70)$ & $83(63)$ & $282(68)$ \\
\hline Exercise history, $n(\%)$ yes & $174(62)$ & $89(79)$ & $263(67)$ \\
\hline \multicolumn{4}{|l|}{ Social-cognitive variables $(0-100)$} \\
\hline Intention, mean (SD) & $77.9(31.3)$ & $61.2(35.8)$ & $72.6(33.7)$ \\
\hline Attitude, mean (SD) & $79.8(21.3)$ & $80.4(21.8)$ & $80.0(21.4)$ \\
\hline Subjective norm, mean (SD) & $73.3(30.1)$ & $55.1(31.8)$ & $67.5(31.8)$ \\
\hline Perceived behavioral control, mean (SD) & $53.6(26.7)$ & $47.3(24.6)$ & $51.7(26.2)$ \\
\hline \multicolumn{4}{|l|}{ Physical activity } \\
\hline Score PASE, median (IQR) points & $106.7(58.3 ; 164.7)$ & & \\
\hline Score IPAQ, median (IQR) MET minutes/week & & $3510(1563 ; 6131)$ & \\
\hline
\end{tabular}

$I P A Q$ International Physical Activity Questionnaire, $I Q R$ interquartile range, $N A$ not assessed, $P A$ physical activity, PASE Physical Activity Scale for the Elderly, $P D T$ photodynamic therapy, $S D$ standard deviation

${ }^{\text {a }}$ One or more out of eight comorbidities strategies to account for the intention-behavior gap [34], and they may be worth further investigation in HNC survivors.

Our finding that younger patients are more physically active confirms results from previous studies in cancer survivors $[9,15,23]$, including HNC [48], and suggests that interventions promoting PA behavior in HNC survivors should particularly target the older ones. Studies among the older, general adult population have observed high levels of sedentary behavior [8], and that PA is hampered by poor health and lack of interest [18] and is facilitated by motivational (e.g., self-efficacy, outcome expectations, goal setting, action planning, and control) and environmental (e.g., neighborhood safety and access to PA) determinants [49]. More research is needed to identify PA barriers and modifiable motivational determinants that should be addressed in interventions specifically aiming to promote PA among older cancer survivors including HNC.

A limited number of studies evaluating PA interventions specifically targeting the elderly cancer population have 
Table 2 Univariable multilevel associations of demographic, clinical, lifestyle-related, and social-cognitive variables with physical activity intention and behavior $(n=416)$

Table 3 Multivariable multilevel associations with PA intention and PA behavior

\begin{tabular}{lll}
\hline & PA intention & PA behavior \\
\hline & $\beta(95 \% \mathrm{CI})$ & $\beta(95 \% \mathrm{CI})$ \\
Demographic & $-0.06(-0.41 ; 0.29)$ & $-0.02(-0.03 ;-0.008)^{*}$ \\
Older age (year) & $-0.45(-8.67 ; 7.77)$ & $0.05(-0.20 ; 0.30)$ \\
Female & $0.41(-6.83 ; 7.65)$ & $0.14(-0.08 ; 0.35)$ \\
Having a partner & $6.72(-0.81 ; 14.26)^{* *}$ & $0.08(-0.15 ; 0.31)$ \\
Higher education & & \\
Clinical & $0.38(-0.11 ; 0.87)$ & $0.007(-0.006 ; 0.02)$ \\
Time since treatment (year) & $1.15(-7.33 ; 9.63)$ & $0.15(-0.06 ; 0.36)$ \\
Multiple treatment modalities & $-6.41(-13.02 ; 0.20)^{* *}$ & $-0.30(-0.50 ;-0.10)^{*}$ \\
Comorbidity & $-9.66(-20.14 ; 0.81)^{* *}$ & $-0.50(-0.81 ;-0.19)^{*}$ \\
Unintentional weight loss & $0.05(-0.68 ; 0.78)$ & $-0.003(-0.02 ; 0.02)$ \\
BMI & & \\
Lifestyle-related & $-0.43(-7.33 ; 6.47)$ & $0.06(-0.14 ; 0.27)$ \\
Current alcohol consumption & $13.60(6.69 ; 20.51)^{*}$ & $0.18(-0.03 ; 0.38)^{* *}$ \\
Exercise history & & $0.007(0.005 ; 0.010)^{*}$ \\
Social cognitive & - & $0.008(0.004 ; 0.011)^{*}$ \\
Intention & $0.40(0.28 ; 0.51)^{*}$ & - \\
PBC & $0.55(0.40 ; 0.69)^{*}$ & - \\
Attitude & $0.32(0.22 ; 0.42)^{*}$ & \\
Subjective norm & $P A$ & \\
\hline BM & & \\
\hline
\end{tabular}

$B M I$ body mass index, $C I$ confidence interval, $P A$ physical activity, $P B C$ perceived behavioral control $* p<0.05 ; * * 0.05 \leq p<0.10$

$\beta(95 \% \mathrm{CI}) \quad$ Explained variances

PA intention

Step 1

$3.6 \%$

Exercise history

$13.60(6.69 ; 20.51)^{*}$

Step 2

Exercise history

$7.56(1.08 ; 14.07)^{*}$

Attitude

$0.39(0.24 ; 0.53)^{*}$

Subjective norm

$0.21(0.11 ; 0.31)^{*}$

PBC

$0.25(0.14 ; 0.37)^{*}$

PA behavior

Step 1

$8.7 \%$

Higher age (year)

$-0.02(-0.03 ;-0.01)^{*}$

$0.02(0.004 ; 0.03)^{*}$

Time since treatment (year)

$-0.45(-0.75 ;-0.15)^{*}$

Unintentional weight loss

Comorbidity

$-0.31(-0.50 ;-0.11)^{*}$

Step 2

Higher age (year)

Time since treatment (year)

Unintentional weight loss

Comorbidity

Intention

$22.9 \%$

$-0.02(-0.03 ;-0.01)^{*}$

$15.8 \%$

$0.01(-0.004 ; 0.02)$

$-0.37(-0.66 ;-0.08) *$

$-0.27(-0.45 ;-0.09)^{*}$

$0.005(0.003 ; 0.008)^{*}$

$0.005(0.001 ; 0.008)^{*}$

$C I$ confidence interval, $P B C$ perceived behavioral control $* p<0.05$ 
Table 4 Model parameter estimated by the structural equation model

\begin{tabular}{lllll}
\hline & Estimate & Standard error & $p$ value & Explained variances \\
\hline Association with PA intention & & & & $22.9 \%$ \\
Attitude & 0.247 & 0.047 & $<0.001$ & \\
Subjective norm & 0.196 & 0.047 & $<0.001$ & \\
PBC & 0.198 & 0.047 & $<0.001$ & \\
Exercise history & 0.106 & 0.047 & 0.02 & \\
Associations with PA behavior & & & & $16.1 \%$ \\
Intention & 0.179 & 0.048 & $<0.001$ & \\
PBC & 0.118 & 0.048 & 0.013 & \\
Age (years) & -0.224 & 0.048 & $<0.001$ & \\
Time since treatment (year) & 0.069 & 0.050 & 0.175 & \\
Unintentional weight loss & -0.115 & 0.047 & 0.014 & \\
Comorbidity & -0.131 & 0.045 & 0.004 & \\
\end{tabular}

$P A$ physical activity, $P B C$ perceived behavioral control shown beneficial effects on physical fitness, functional independence, and quality of life [26]. However, such interventions are complicated by the relatively high proportion of comorbidities present in the elderly cancer population [26]. We confirmed the finding that comorbidities may form a barrier to PA in HNC survivors [35], and this was independent from age. It is therefore important to gain more understanding on how to motivate and support patients with comorbidities to be physically active. PA promotion interventions should be tailored to the specific comorbidities of individual cancer survivors [47]. Specific attention must also be paid to unintentional weight loss, as this may indicate malnutrition, forming a barrier to PA behavior. Additional nutritional counseling should be recommended for patients with malnutrition [6].
Previous research has demonstrated that demographic and clinical correlates of PA may differ across cancer types [15]. This, in fact, provided the rationale for investigating correlates of PA in HNC survivors. The lack of significant associations observed for most demographic and clinical variables with PA confirms findings from previous studies in HNC survivors [39, 48], although results from a study by Rogers et al. [35] suggested that $\mathrm{HNC}$-specific symptoms may form barriers to PA. Clinical variables and associated symptoms may be more strongly associated with PA in patients during or shortly their cancer treatment, compared to patients who completed treatments longer ago, as in our sample. Prospective studies in the HNC population are therefore warranted, to determine the extent to which correlates of PA behavior remain stable or vary over the cancer (treatment) continuum [39].

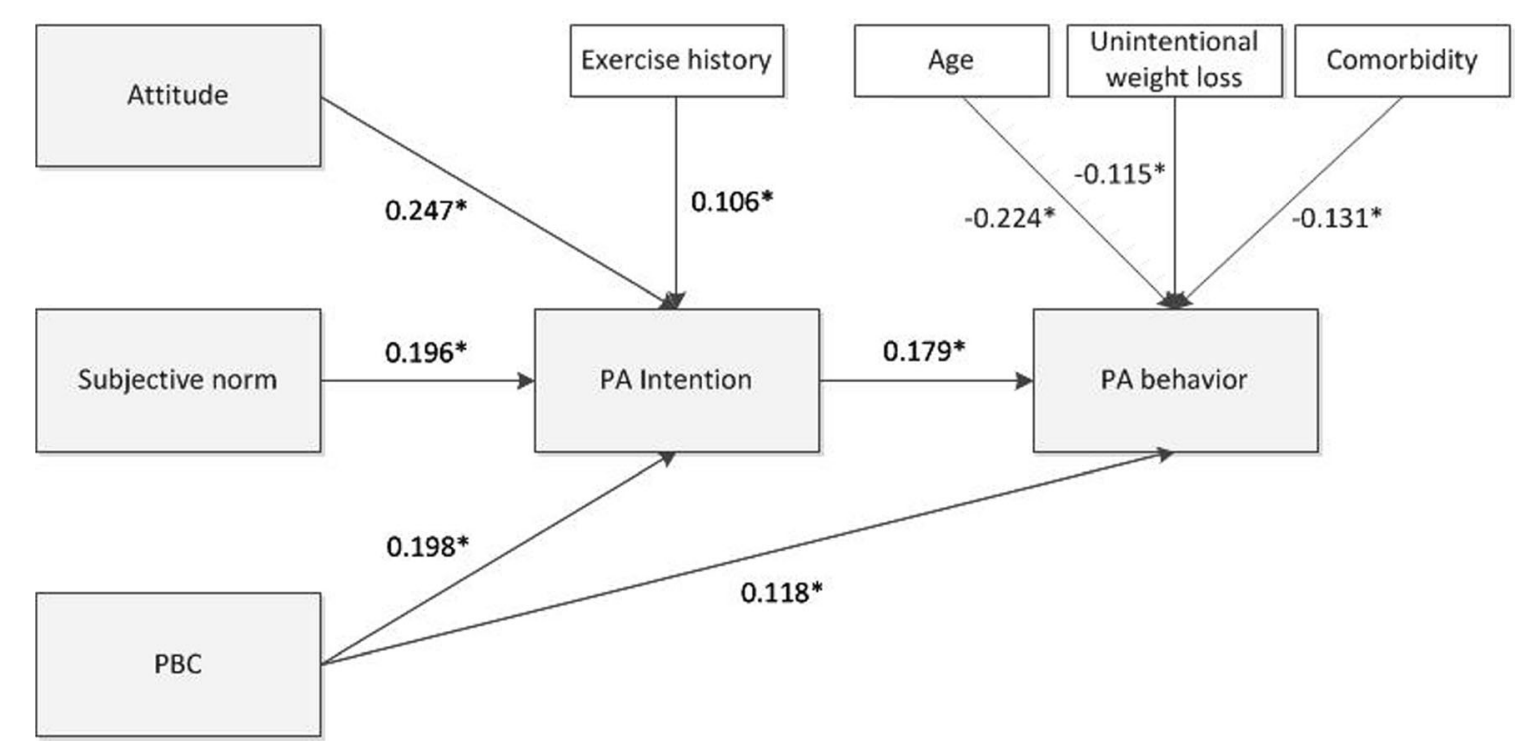

Fig. 1 Standardized parameter estimates for the theory of planned behavior model in head and neck cancer survivors. PA physical activity, PBC perceived behavioral control. ${ }^{*} p<0.05$ 
We found that exercise history was associated significantly with PA intention, which, according to the TPB model, is the main factor driving PA behavior [5]. Habits have been recognized as an important determinant of behavior [16], both in initiating and in performing a behavior [17]. Our study found an association between habits and PA intention, but not with behavior. It may be that longer term survivors have developed a new lifestyle that is less strongly associated with pre-cancer behavior. Our finding in this regard should, however, be interpreted with caution because the majority of the HNC survivors in our study reported having a history of exercising, but this was based on self-report. This may have introduced recall bias [38], particularly in longer term survivors.

Strengths of this study are the application of the TPB model with path analyses in a large group of HNC survivors. Nevertheless, the study had several limitations. First, to obtain the large sample, data from two studies with a different recruitment strategy were merged. In both studies, response rates were relatively low, and it may be that those who were more interested in PA were more likely to participate. This may have resulted in an overestimation of PA levels. Additionally, laryngectomized survivors were overrepresented in our sample of HNC survivors. This hampers the generalizability of the results to all patients with HNC. The observed associations, however, are most likely valid. Second, PA behavior was assessed using two different self-report measures, with $Z$ scores being calculated to enable pooling. Despite the use of validated questionnaires, self-reports are prone to recall bias and likely to overreport or underreport PA levels. Additionally, by transforming the scores using a standardized value of the log-transformed scores, the clinical meaning of the regression coefficients can no longer be directly inferred. Yet, the relative importance of each explanatory variable can still be judged from the analyses. Third, we assessed attitude, subjective norm, and PBC directly and were not able to incorporate the underlying beliefs, as they were not assessed in a similar way across the studies. The failure to include these underlying beliefs in our models may have contributed, in part, to the low levels of explained variances in PA intention and behavior that were observed. Finally, due to the cross-sectional design, no inferences can be made regarding causality.

Considering the positive association between PA and HRQoL in HNC survivors [36, 39, 48], it may be important to develop interventions to improve PA in this population. The effectiveness of such interventions may be improved by applying appropriate behavior change theories and strategies [44]. Our results showed that the TPB model alone may be of only limited value in explaining PA behavior, and thus in designing interventions to promote PA in $\mathrm{HNC}$ survivors. Interventions to promote PA in HNC survivors should specifically address barriers associated with, e.g., comorbidity and poor nutritional status, and not rely solely on improving $\mathrm{PBC}$ and intention. The development of such interventions should consider using models that account for the intention-behavior gap.

Acknowledgements We would like to thank all of the HNC survivors who participated in the studies reported in this paper.

\section{Compliance with ethical standards}

Conflict of interest The authors declare that they have no conflict of interest.

Open Access This article is distributed under the terms of the Creative Commons Attribution-NonCommercial 4.0 International License (http:// creativecommons.org/licenses/by-nc/4.0/), which permits any noncommercial use, distribution, and reproduction in any medium, provided you give appropriate credit to the original author(s) and the source, provide a link to the Creative Commons license, and indicate if changes were made.

\section{References}

1. Ahlberg A, Engstrom T, Nikolaidis P, Gunnarsson K, Johansson H, Sharp L, Laurell G (2011) Early self-care rehabilitation of head and neck cancer patients. Acta Otolaryngol 131(5):552-561. https://doi. org/10.3109/00016489.2010.532157

2. Ainsworth BE, Haskell WL, Herrmann SD, Meckes N, Bassett DR Jr, Tudor-Locke C, Greer JL, Vezina J, Whitt-Glover MC, Leon AS (2011) 2011 compendium of physical activities: a second update of codes and MET values. Med Sci Sports Exerc 43(8):1575-1581. https://doi.org/10.1249/MSS.0b013e31821 ece12

3. Ainsworth BE, Haskell WL, Leon AS, Jacobs DR Jr, Montoye HJ, Sallis JF, Paffenbarger RS Jr (1993) Compendium of physical activities: classification of energy costs of human physical activities. Med Sci Sports Exerc 25(1):71-80. https://doi.org/10.1249/ 00005768-199301000-00011

4. Ainsworth BE, Haskell WL, Whitt MC, Irwin ML, Swartz AM, Strath SJ, O’Brien WL, Bassett DR Jr, Schmitz KH, Emplaincourt PO, Jacobs DR Jr, Leon AS (2000) Compendium of physical activities: an update of activity codes and MET intensities. Med Sci Sports Exerc 32(Supplement):S498-S504. https://doi. org/10.1097/00005768-200009001-00009

5. Ajzen I (1991) The theory of planned behavior. Organ Behav Hum Decis Process 50(2):179-211. https://doi.org/10.1016/07495978(91)90020-T

6. Arends J, Bachmann P, Baracos V, Barthelemy N, Bertz H, Bozzetti F, Fearon K, Hutterer E, Isenring E, Kaasa S, Krznaric Z, Laird B, Larsson M, Laviano A, Muhlebach S, Muscaritoli M, Oldervoll L, Ravasco P, Solheim T, Strasser F, de van der Schueren M, Preiser JC (2017) ESPEN guidelines on nutrition in cancer patients. Clin Nutr 36(1):11-48. https://doi.org/10.1016/j.clnu.2016.07.015

7. Blanchard CM, Courneya KS, Rodgers WM, Murnaghan DM (2002) Determinants of exercise intention and behavior in survivors of breast and prostate cancer: an application of the theory of planned behavior. Cancer Nurs 25(2):88-95. https://doi.org/10. 1097/00002820-200204000-00002

8. Brug J, Chinapaw M (2015) Determinants of engaging in sedentary behavior across the lifespan; lessons learned from two systematic reviews conducted within DEDIPAC. Int J Behav Nutr Phys Act 12(1):134. https://doi.org/10.1186/s12966-015-0293-2 
9. Buffart LM, Thong MS, Schep G, Chinapaw MJ, Brug J, van de Poll-Franse LV (2012) Self-reported physical activity: its correlates and relationship with health-related quality of life in a large cohort of colorectal cancer survivors. PLoS One 7:e36164

10. Carvalho AP, Vital FM, Soares BG (2012) Exercise interventions for shoulder dysfunction in patients treated for head and neck cancer. Cochrane Database Syst Rev (4):CD008693

11. Cnossen IC, van Uden-Kraan CF, Rinkel RN, Aalders IJ, de Goede CJ, de Bree R, Doornaert P, Rietveld DH, Langendijk JA, Witte BI, Leemans CR, Verdonck-de Leeuw IM (2014) Multimodal guided self-help exercise program to prevent speech, swallowing, and shoulder problems among head and neck cancer patients: a feasibility study. J Med Internet Res 16(3):e74. https://doi.org/10.2196/ jmir.2990

12. Courneya KS, Friedenreich CM (1997) Relationship between exercise pattern across the cancer experience and current quality of life in colorectal cancer survivors. J Altern Complement Med 3(3):215226. https://doi.org/10.1089/acm.1997.3.215

13. Courneya KS, Friedenreich CM (1999) Utility of the theory of planned behavior for understanding exercise during breast cancer treatment. Psychooncology 8(2):112-122. https://doi.org/10.1002/ (SICI)1099-1611(199903/04)8:2<112::AID-PON341>3.0.CO;2-L

14. Craig CL, Marshall AL, Sjostrom M, Bauman AE, Booth ML, Ainsworth BE, Pratt M, Ekelund U, Yngve A, Sallis JF, Oja P (2003) International physical activity questionnaire: 12-country reliability and validity. Med Sci Sports Exerc 35(8):1381-1395. https://doi.org/10.1249/01.MSS.0000078924.61453.FB

15. Forbes CC, Blanchard CM, Mummery WK, Courneya KS (2014) A comparison of physical activity correlates across breast, prostate and colorectal cancer survivors in Nova Scotia, Canada. Support Care Cancer 22(4):891-903. https://doi.org/10.1007/s00520-0132045-7

16. Gardner B (2015) A review and analysis of the use of 'habit' in understanding, predicting and influencing health-related behaviour. Health Psychol Rev 9(3):277-295. https://doi.org/10.1080/ 17437199.2013.876238

17. Gardner B, Phillips LA, Judah G (2016) Habitual instigation and habitual execution: definition, measurement, and effects on behaviour frequency. Br J Health Psychol 21(3):613-630. https://doi.org/ 10.1111/bjhp.12189

18. Gellert P, Witham MD, Crombie IK, Donnan PT, McMurdo ME, Sniehotta FF (2015) The role of perceived barriers and objectively measured physical activity in adults aged 65-100. Age Ageing 44(3):384-390. https://doi.org/10.1093/ageing/afv001

19. Glanz K, Bishop DB (2010) The role of behavioral science theory in development and implementation of public health interventions. Annu Rev Public Health 31(1):399-418. https://doi.org/10.1146/ annurev.publhealth.012809.103604

20. Hunter KU, Jolly S (2013) Clinical review of physical activity and functional considerations in head and neck cancer patients. Support Care Cancer 21(5):1475-1479. https://doi.org/10.1007/s00520013-1736-4

21. Irwin ML, Crumley D, McTiernan A, Bernstein L, Baumgartner R, Gilliland FD, Kriska A, Ballard-Barbash R (2003) Physical activity levels before and after a diagnosis of breast carcinoma: the Health, Eating, Activity, and Lifestyle (HEAL) study. Cancer 97(7):17461757. https://doi.org/10.1002/cncr.11227

22. Johnson CD (2014) Extension of Nakagawa \& Schielzeth's $\mathrm{R}^{2 \mathrm{GLMM}}$ to random slope models. Methods Ecol Evol 5(9):944946. https://doi.org/10.1111/2041-210X.12225

23. Kampshoff CS, Stacey F, Short CE, van Mechelen W, Chinapaw MJ, Brug J, Plotnikoff R, James EL, Buffart LM (2016) Demographic, clinical, psychosocial, and environmental correlates of objectively assessed physical activity among breast cancer survivors. Support Care Cancer 24(8):3333-3342. https://doi.org/10. 1007/s00520-016-3148-8
24. Karvinen KH, Courneya KS, Campbell KL, Pearcey RG, Dundas G, Capstick V, Tonkin KS (2007) Correlates of exercise motivation and behavior in a population-based sample of endometrial cancer survivors: an application of the theory of planned behavior. Int J Behav Nutr Phys Act 4(1):21. https://doi.org/10.1186/1479-58684-21

25. Karvinen KH, Courneya KS, Plotnikoff RC, Spence JC, Venner PM, North S (2009) A prospective study of the determinants of exercise in bladder cancer survivors using the theory of planned behavior. Support Care Cancer 17(2):171-179. https://doi.org/10. 1007/s00520-008-0471-8

26. Klepin HD, Mohile SG, Mihalko S (2013) Exercise for older cancer patients: feasible and helpful? Interdiscip Top Gerontol 38:146157. https://doi.org/10.1159/000343597

27. Koay K, Schofield P, Gough K, Buchbinder R, Rischin D, Ball D, Corry J, Osborne RH, Jefford M (2013) Suboptimal health literacy in patients with lung cancer or head and neck cancer. Support Care Cancer 21(8):2237-2245. https://doi.org/10.1007/s00520-013$1780-0$

28. Lefcheck JS (2016) Piecewise SEM: piecewise structural equation modelling in $\mathrm{R}$ for ecology, evolution and systematics. Methods Ecol Evol 7(5):573-579. https://doi.org/10.1111/2041-210X.12512

29. Liu RD, Buffart LM, Kersten MJ, Spiering M, Brug J, van Mechelen W, Chinapaw MJ (2011) Psychometric properties of two physical activity questionnaires, the AQuAA and the PASE, in cancer patients. BMC Med Res Methodol 11(1):30. https://doi. org/10.1186/1471-2288-11-30

30. Lonbro S, Dalgas U, Primdahl H, Overgaard J, Overgaard K (2013) Feasibility and efficacy of progressive resistance training and dietary supplements in radiotherapy treated head and neck cancer patients-the DAHANCA 25A study. Acta Oncol 52(2):310-318. https://doi.org/10.3109/0284186X.2012.741325

31. Mishra SI, Scherer RW, Geigle PM, Berlanstein DR, Topaloglu O, Gotay CC, Snyder C (2012) Exercise interventions on healthrelated quality of life for cancer survivors. Cochrane Database Syst Rev 8:CD007566

32. Mishra SI, Scherer RW, Snyder C, Geigle PM, Berlanstein DR, Topaloglu O (2012) Exercise interventions on health-related quality of life for people with cancer during active treatment. Cochrane Database Syst Rev 8:CD008465

33. Nakagawa S, Schielzeth H (2013) A general and simple method for obtaining $\mathrm{R}^{2}$ from generalized linear mixed-effects models. Methods Ecol Evol 4(2):133-142. https://doi.org/10.1111/j.2041210x.2012.00261.x

34. Rhodes RE, Yao CA (2015) Models accounting for intentionbehavior discordance in the physical activity domain: a user's guide, content overview, and review of current evidence. Int $\mathrm{J}$ Behav Nutr Phys Act 12(1):9. https://doi.org/10.1186/s12966015-0168-6

35. Rogers LQ, Courneya KS, Robbins KT, Malone J, Seiz A, Koch L, Rao K (2008) Physical activity correlates and barriers in head and neck cancer patients. Support Care Cancer 16(1):19-27. https://doi. org/10.1007/s00520-007-0293-0

36. Rogers LQ, Courneya KS, Robbins KT, Malone J, Seiz A, Koch L, Rao K, Nagarkar M (2006) Physical activity and quality of life in head and neck cancer survivors. Support Care Cancer 14(10):10121019. https://doi.org/10.1007/s00520-006-0044-7

37. Rogers LQ, Fogleman A, Verhulst S, Bhugra M, Rao K, Malone J, Robbs R, Robbins KT (2015) Refining measurement of social cognitive theory factors associated with exercise adherence in head and neck cancer patients. J Psychosoc Oncol 33(5):467-487. https://doi. org $/ 10.1080 / 07347332.2015 .1067277$

38. Sallis JF, Saelens BE (2000) Assessment of physical activity by self-report: status, limitations, and future directions. Res Q Exerc Sport 71(Suppl 2):1-14. https://doi.org/10.1080/02701367.2000. 11082780 
39. Sammut L, Fraser LR, Ward MJ, Singh T, Patel NN (2016) Participation in sport and physical activity in head and neck cancer survivors: associations with quality of life. Clin Otolaryngol 41(3): 241-248. https://doi.org/10.1111/coa.12506

40. Shipley B (2000) A new inferential test for path models based on directed acyclic graphs. Struct Equ Model: Multidiscip J 7(2):206-218. https://doi.org/10.1207/ S15328007SEM0702 4

41. Shipley B (2009) Confirmatory path analysis in a generalized multilevel context. Ecology 90(2):363-368. https://doi.org/10.1890/081034.1

42. Speck RM, Courneya KS, Masse LC, Duval S, Schmitz KH (2010) An update of controlled physical activity trials in cancer survivors: a systematic review and meta-analysis. J Cancer Surviv 4(2):87-100. https://doi.org/10.1007/s11764-009-0110-5

43. Speed-Andrews AE, Rhodes RE, Blanchard CM, Culos-Reed SN, Friedenreich CM, Belanger LJ, Courneya KS (2012) Medical, demographic and social cognitive correlates of physical activity in a population-based sample of colorectal cancer survivors. Eur $\mathbf{J}$ Cancer Care (Engl) 21(2):187-196. https://doi.org/10.1111/j.13652354.2011.01290.x

44. Stacey FG, James EL, Chapman K, Courneya KS, Lubans DR (2015) A systematic review and meta-analysis of social cognitive theory-based physical activity and/or nutrition behavior change interventions for cancer survivors. J Cancer Surviv 9(2):305-338. https://doi.org/10.1007/s11764-014-0413-z

45. Trinh L, Plotnikoff RC, Rhodes RE, North S, Courneya KS (2012) Correlates of physical activity in a population-based sample of kidney cancer survivors: an application of the theory of planned behavior. Int J Behav Nutr Phys Act 9(1):96. https://doi.org/10.1186/ 1479-5868-9-96

46. Vallerand JR, Rhodes RE, Walker GJ, Courneya KS (2016) Explaining the aerobic exercise intention-behavior gap in cancer survivors. Am J Health Behav 40(5):675-684. https://doi.org/10. 5993/AJHB.40.5.15

47. van der Leeden M, Huijsmans RJ, Geleijn E, de Rooij M, Konings IR, Buffart LM, Dekker J, Stuiver MM (2017) Tailoring exercise interventions to comorbidities and treatment-induced adverse effects in patients with early stage breast cancer undergoing chemotherapy: a framework to support clinical decisions Disabil Rehabil: 1-11. doi: https://doi.org/10.1080/09638288.2016.1260647

48. Van Nieuwenhuizen AJ, Buffart LM, Van Uden-Kraan CF, van der Velden LA, Lacko M, Brug J, Leemans CR, Verdonck-de Leeuw IM (2016) Patient reported physical activity and the association with health related quality of life in head and neck cancer survivors. Submitted

49. van Stralen MM, de Vries H, Mudde AN, Bolman C, Lechner L (2009) Determinants of initiation and maintenance of physical activity among older adults: a literature review. Health Psychol Rev 3(2):147-207. https://doi.org/10.1080/17437190903229462

50. Washburn RA, McAuley E, Katula J, Mihalko SL, Boileau RA (1999) The physical activity scale for the elderly (PASE): evidence for validity. J Clin Epidemiol 52(7):643-651. https://doi.org/10. 1016/S0895-4356(99)00049-9

51. Washburn RA, Smith KW, Jette AM, Janney CA (1993) The Physical Activity Scale for the Elderly (PASE): development and evaluation. J Clin Epidemiol 46(2):153-162. https://doi.org/10. 1016/0895-4356(93)90053-4

52. Washburn RA, Zhu W, McAuley E, Frogley M, Figoni SF (2002) The physical activity scale for individuals with physical disabilities: development and evaluation. Arch Phys Med Rehabil 83(2):193200. https://doi.org/10.1053/apmr.2002.27467

53. Zhao SG, Alexander NB, Djuric Z, Zhou J, Tao Y, Schipper M, Feng FY, Eisbruch A, Worden FP, Strath SJ, Jolly S (2016) Maintaining physical activity during head and neck cancer treatment: results of a pilot controlled trial. Head Neck 38(Suppl 1): E1086-E1096. https://doi.org/10.1002/hed.24162 